\title{
A Faired Quality of Service Assured MAC PROTOCOL FOR MOBILE ADHOC NETWORK \& ITS Performance Evaluation
}

\author{
D.D.Seth ${ }^{1,}$ Srikanta Patnaik ${ }^{2}$ and Srikanta Pal $^{3}$ \\ ${ }^{1}$ School of Electronics, KIIT University, Bhubaneswar, Odisha, India \\ ddgayatri@yahoo.co.in \\ ${ }^{2}$ Interscience Institute of Technology \& Management, Bhubaneswar, Odisha, India \\ patnaik_srikanta@yahoo.co.in \\ ${ }^{3}$ Department of Electronics and Communication Engineering, Birla Institute of \\ Technology, Mesra, Ranchi, India \\ pal_srikanta@yahoo.co.uk
}

\begin{abstract}
The medium access control (MAC) protocol for Mobile Adhoc Network (MANET) need to be distributed, QoS assured, fair to all flows and should work in a multihop environment. Although there are numerous MAC protocol proposed for MANET, very few of them possesses all the above properties. This paper, which proposes a MAC protocol for adhoc network have all the above mentioned properties. The protocol supports quality of service and exhibit flow based fairness over multihop adhoc network. In accordance with the protocol, high prioritized traffic flows are allowed to access the channel earlier than the low prioritized traffic flows. If multiple numbers of flows of the same priority level are active in the network then the fairness factor comes into account. The less served flow, and then gets the priority over the highly served flow in accessing the channel. The performance of the protocol is evaluated analytically. The result shows that the high prioritized traffic flow experience less delay and have more throughputs as compared to others.
\end{abstract}

\section{KEYWORDS}

MANET, QoS, DCF,Fairness,Saturation Throughput

\section{INTRODUCTION}

In the past decade wireless networks have experienced unprecedented development. Mobile Adhoc Network (MANET) is one of the most rapidly developing areas. Briefly adhoc networks are stand-alone wireless networks that lack the services of a backbone infrastructure. They consist only of a collection of mobile stations voluntarily act as forwarders or routers for other mobile stations in the network. Such networks are initially designed for use in military and emergency-relief application. Lately, by virtue of better spatial reuse characteristics in comparison to the conventional wireless network model [1] they are used in regular wireless network application, sensor network, and personal area networks.

Most of the research works on routing and transport layer protocols in adhoc networks assume the use of CSMA/CA as the Medium Access Control (MAC) protocol in their protocol stacks. The very reasons for the assumption are (i) the infrastructure-less mode of operation that the 
IEEE 802.11 DCF supports (ii) the popularity of the IEEE standard itself that requires no additional hardwires for the adhoc mode of operation.

The explosive growth of multimedia application has arisen the problem of the required Quality of Service (QoS) of these applications such as guaranteed delay, jitter and bandwidth. Although IEEE 802.11 DCF has gained the momentum and popularity in recent times and has become the de-facto standard for adhoc networks, it has some limitations.(a)It does not support Quality of Service (QoS). That means it does not differentiate between the bandwidth and delay sensitive real time traffics (RT) and non sensitive non-real time (n-RT) traffics. (b) It is also poor with regard to fairness. A channel is said to be fair if it is able to provide each and every individual nodes without giving preference to one node over the others when there is no service differentiation. As in IEEE 802.11 DCF, the successful node (the node which successfully transmitted the packet) sets its contention window to $\mathrm{CW}_{\min }$ where as collided node (the node which experiences collision) sets its contention window to $2 * \mathrm{CW}_{\text {old }}$. Hence the successful nodes remain in a better position to transmit the next packet in comparison to the collided nodes. This leads to unfairness. (c) This IEEE 802.11 DCF performs poorly in a multihop adhoc network. In a multihop adhoc networks the intermediate nodes not only have to transmit their own generated packets but also have to forward the packets of other nodes. Hence in absence of proper queue management at the MAC level overall throughput decreases.

A new Medium Access Control (MAC) protocol has been proposed in this work by extending the mandatory Distributed coordinated Function (DCF) of the MAC sub layer. The proposed protocol has the following features.(i) Distributed in nature (ii) Supports Quality of Service (QoS) (iii)Exhibits fairness (iv) Applicable to Multihop adhoc network (v) Avoids hidden node problem. The performance evaluation model for the protocol has also been introduced.

The rest of the paper is organized as follows. Section II discusses the related work in this field. Section III give the detailed description of the proposed protocol, In Section IV Analytical model and performance evaluation described in Section V. Section VI discusses the results. Concluding remark and suggestion for future work is included in Section VII. This document describes, and is written to conform to, author guidelines for the journals of AIRCC series. It is prepared in Microsoft Word as a .doc document. Although other means of preparation are acceptable, final, camera-ready versions must conform to this layout. Microsoft Word terminology is used where appropriate in this document. Although formatting instructions may often appear daunting, the simplest approach is to use this template and insert headings and text into it as appropriate.

\section{RELATED WORK}

In recent times a number of medium access control (MAC) protocol supporting quality of service has been proposed. Some of the protocol ensures quality of service but very poor with respect to fairness. Others although assures QoS for one hop performs poorly when it is applied to a multihop network. Some of the protocols proposed in this field are described in the following section. As the medium access control (MAC) protocol proposed in this thesis is based on IEEE 802.11 DCF [2], it is discussed in the following subsection.

\subsection{DCF (Distributed Coordination Function)[2]}

IEEE 802.11 DCF is an implementation of CSMA /CA protocol which follows four way handshaking (RTS/CTS/DATA/ACK) for data transmission. Whenever a station is ready to transmit data, it senses the channel for DIFS period and when it observe that the channel is idle for this period, it generates a random back off timer chosen uniformly from a $(0, \mathrm{CW}-1)$, where $\mathrm{CW}=$ contention window. After the back off timer expires, it sends a RTS packet to the 
destination node. If the destination node is ready to receive the data, it replies with a CTS packet. Both RTS and CTS messages carry the duration information for which the channel is going to be occupied by the proposed data transmission. All other nodes in the vicinity of the sender and destination update their NAV (Network Allocation Vector) with the information for which channel is going to be busy. Hence possibility of collision is reduced as those stations defer their transmission and reception. The CTS message is followed by the DATA transmission which is acknowledged by the receiver by sending an ACK message if the DATA is received successfully. The data is repeatedly retransmitted in the absence of ACKs till a threshold number of retransmissions are carried out. Once the retransmissions exceed the threshold, the transmission is assumed to be unsuccessful. After an unsuccessful transmission attempt, the sender follows a binary exponential back off (BEB) and doubles its contention window size. This is done in order to reduce the channel contention between nodes. The contention window is not incremented further if it already equals CWmax. The contention is reset back to CWmin, after every successful transmission. RTS, CTS, DATA, and ACK are separated by a time spacing of Short Inter Frame Space (SIFS).

The IEEE 802.11 DCF in its original form does not support service differentiation. It give similar treatments to all types of packet and all stations contend for the channel with same argument by which the $\mathrm{CW}$ is set and $\mathrm{BEB}$ (binary exponential back off ) algorithm is run. Hence the delay sensitive traffics may experience intolerable delay and required Quality of Service (QoS) is not maintained by using the legacy IEEE 802.11 DCF.

Further, CSMA/CA protocol suffers from fairness problem. Initially all the stations have equal opportunity to access the channel. But after successful transmission the station sets its CW size to $\mathrm{CWmin}$ whereas the collided station doubles its $\mathrm{CW}$ size. Hence a successful node remains always in a better position to access the channel as compared to unsuccessful one, which leads to unfairness. The unfairness of MAC has a far reaching impact on the behavior of higher layer protocols and the applications using the network. Application like audio/video streaming are sensitive to packet delays and jitters. When the underlying link behavior is unfair, some applications may be starved of bandwidth just because their share is unfairly distributed somewhere else.

Although IEEE 802.11 MAC support some kind of adhoc network architecture it is not intended to support the wireless mobile adhoc network, in which multi-hop connectivity is one of the most prominent features[17] .It is seen that 802.11 based multihop wireless network suffer from serious exposed node problem and collisions. This MAC layer problem may cause the failure of routing protocol.From the above discussion, it is clear that the legacy 802.11 DCF need to be modified to work in a multihop adhoc network.

\subsection{Related works on QoS}

EDCF is the distributed medium access control protocol [9] is the enhanced version of DCF. It supports service differentiation by employing eight priority classes. Although it supports Quality of Service, it does not address fairness and multihop issue.

Black Burst [4] protocol provides QoS by jamming the channel through pulses of energy for the node with time sensitive traffics. It continues to access the channel until all the packets are transmitted. Again it does not fully consider the fairness as well as the multihop issues.

DBASE [3] protocol supports both data and multimedia traffic over the IEEE 802.11 adhoc network. Nodes with real time traffics (RT-node) are prioritized higher than the non-real time node by choosing a shorter observation period. In this protocol bandwidth is allocated among the nodes according to their requirement in the next cycle. But the allocation does not exceed 
International Journal of Wireless \& Mobile Networks (IJWMN) Vol. 3, No. 2, April 2011

the average bandwidth requirement. The bandwidth requirement in the next cycle, if, lower than the present bandwidth, the residual bandwidth can be shared with the needy nodes. The bandwidth so shared can be withdrawn when own requirement exceeds. Although this protocol is a noble one in providing QoS, it also does not consider the cases of multihop adhoc network. Fairness issue also not addressed.

TCMA [7] is a QoS based distributed MAC protocol. It is a CSMA/CA protocol. It provides prioritization to different traffics in terms of arbitration time, persistence factor and MAC layer dwell-time limit.TCMA provides QoS in single hop and does not discusses the fairness issue at all. It has no explanation for multihop scenario. Hidden node problem and exposed node problems are also not addressed here.

The above protocols $[9,4,3,7]$ and other protocols such as [5,6,8] supports service differentiation and provide special treatment to bandwidth-delay sensitive real time traffic. But these protocols are not fully faired. Further they are suitable for single hop adhoc network and do not address the issues involved in a multihop scenario.

\subsection{Distributed Fair Scheduling (DFS) [10]}

Distributed Fair Scheduling is a protocol which allows the stations to contend for the channel with the contention window in proportion to the weight assigned to them. The stations with higher weight set the contention window of less size compared to the other stations. Although the DFS protocol deals with fairness issue to a large extent it is however, not clear how the channel shares $\Phi_{i}$ is assigned to each node. It provides node based fairness. That means all node should be fairly served. Node based fairness may cause problem when it is to be applied to a multihop adhoc network. Due to possibility of some nodes (such as intermediate node) servicing more flows than the other, a per - node fairness will cause the degradation of performance. Hence in such situation, flow based fairness is the best choice. Our proposed protocol has been designed taking this point into consideration. The other protocols such as Dugar and Vaidya [12] also discusses the fairness issue.

\subsection{QCMA (Queue-driven Cut-through Multiple Access) [16]}

Legacy IEEE 802.11 DCF is for single hop adhoc network. The performance of DCF in multihop adhoc network has been studied in [17]. It performs very poorly with respect to throughput as well as delay in such Multihop case. QCMA is a recent algorithm proposed by D. Raguin \& others to overcome the inefficiency of IEEE 802.11 DCF protocol for multihop adhoc network. In a multihop adhoc network, the intermediate node may require frequent channel access to forward the packets of the other node. This QCMA protocol has presented a noble idea for access procedure in multihop adhoc network. However it does not address the fairness issue as well as QoS issue.

The related work on the performance analysis may be presented as follows. The performance of the IEEE 802.11 DCF [20] has been investigated based on the Discrete Time Markov Chain (DTMC) model. The saturation throughput analysis employed the Markov chain model and it considered several assumptions namely: (i) saturation condition, (ii) no hidden terminals, (iii) no capture effect, (iv) constant packet arrival rate for all the stations, (v) same radio conditions for all the stations and (vi) no transmission error. These assumptions are not suitable for real wireless environment. A lot of works has been carried out to evaluate the performance of IEEE 802.11 DCF over ideal error-free channel. Earlier studies [25-27] have presented the influence of the physical layer on the MAC layer performance. 


\section{PROPOSED PROTOCOL}

In this section, the detailed description of the protocol is given. This protocol employs the IEEE 802.11 as a subroutine for channel contention. The proposed protocol which is designed for the MAC layer of adhoc network and has the following key features: (1) It supports quality of service (2) It provides flow based fairness. That means it exhibits fairness to different flows but of the same priority class. (3) It also works in a multihop adhoc network. The detailed working of the protocol is given through the flow chart in Figure: 2and 3. In order to provide service differentiation to different types of traffic different priority level is assigned. Hence if the traffic is of higher priority level, it will contend for the channel with a lower CWmin and CWmax. In this work, three types of traffics are involved: voice traffic (constant bit rate), video traffic (variable bit rate) and datagram traffic. The priority level assigned to voice, video and data are $2,1 \& 0$ respectively. Hence voice traffic will contend the channel with less contention window size and data traffic with larger window size. Typically, CWmin and CWmax has been taken as $(7,15),(15,31)$ and $(31,1023)$ for priority class 2,1 and 0 respectively. When the MAC protocol is to be applied in a multihop environment, it becomes a new challenge. Because the intermediate nodes not only have to transmit own generated traffic but also have to forward the packets received from its previous nodes.

\subsection{Enque operation}

Each node maintains three queues q2, q1, q0 to enque the packets of different priority class 2,1 and 0.After receiving the packet and knowing the type of traffic they are enqued in their respective queues. As per the priority level, the queues are dequed.In our work the queue maintained for voice traffic that is q2 is attended first then q2 and lastly q1.The operations are explained through flow chart in Figure 2. Initially set the serv_flow $=1$ for all flows on seeing the packets of those flow for the first time, where serv_flow is the number of service obtained by the flow in the network. It is simply the number of packets of the particular flow has reached the destination successfully. So when the packets pass to the intermediate node, they also make the record of the serv_flow along with the ID of the flow in the locally maintained table of serv_flow. When the intermediate stations receive the packets of a new flow they set the serv_flow=1 with flow ID locally. When the packet finally reaches to the destination the destination node will reply with a ACK. On receiving the ACK, the intermediate node increment serv_flow of the concerned flow by 1 and forward the ACK to the downstream node upto source node of the particular flow. Hence on sending the $1^{\text {st }}$ packet of a particular flow successfully to the destination, all the nodes passed by the flow have set the serv_flow $=2$. So each node keep record of the services obtained by each flow generated and passing through it. When the packets of two different flows but of same priority has been enqued in IFQ(interface queue), the packet belonging to the minimum served flow is dequed. The node contends for the access of the channel with a contention window as follows.

$$
C W=\text { scaling_factor } * C W^{i}
$$

Where, scaling_factor $=$ serv_PF/ serv_BSF

serv_PF $=$ number of service obtained by the current flow in question \& serv_BOF $=$ number of service obtained by the better of the other flows of same priority class $\& \mathrm{CW}^{\mathrm{i}}=$ contention window corresponding to the priority class ' $\mathrm{i}$ '. Hence station will reset the contention window for accessing the channel for the packets of a given flow with

$$
\begin{aligned}
& C \text { Wmin }=\text { scaling_factor } * C W^{i}{ }_{\text {min }} \\
& C \text { Wmax }=\text { scaling_factor } * C W^{i}{ }_{\text {max }}
\end{aligned}
$$


International Journal of Wireless \& Mobile Networks (IJWMN) Vol. 3, No. 2, April 2011

From the above expression it may be observed that scaling factor will be less than 1, when service obtained by the present flow is less than the other flows. Hence it will contend for the channel with still less contention windows.

The working of the proposed protocol is described in flow charts (Figure $2 \& 3$ )

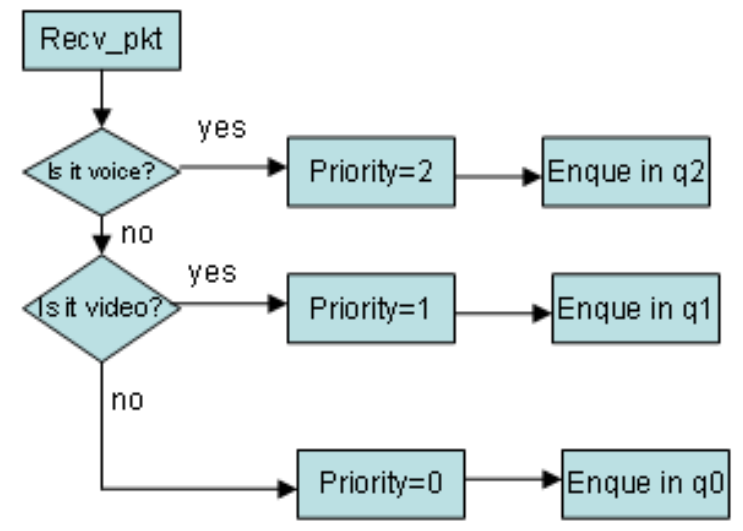

Figure:2: Flow Chart for Enque Operation

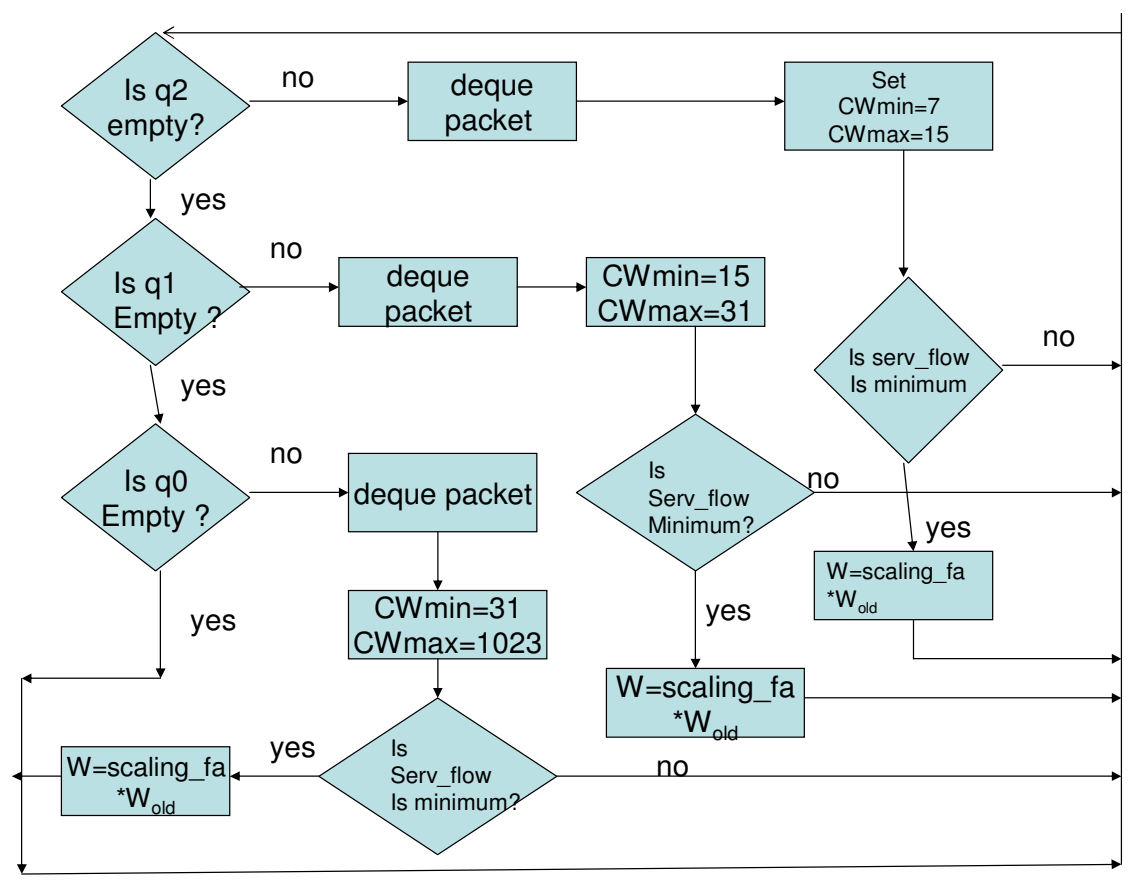

Figure: 3 Flow chart for Deque operation

\subsection{Deque Operation:}

Figure: 3 explains the details of how the packets are dequed and processed.q 2 the highest priority queue is checked first and if it found to be non -empty, the packet is dequed.The contention window is set for that prioritized traffic, which is typically taken as 7,15 in this 
work. Then CWsize is multiplied by the scaling factor. If the number of service obtained by the flow to which the packet belongs to is less compared to the minimum service among other flows then the CWsize will be reduced and the node will contend for the channel with a less window size for the packet belonging to less served flow. If the service obtained by the concerned flow is more than the minimum served flow the contention window size will be set more. The operations are repeated until all the queues are empty.

Illustration with an example: The protocol is explained by taking an example of a simple multihop adhoc network with different flows as shown in the Figure: 4
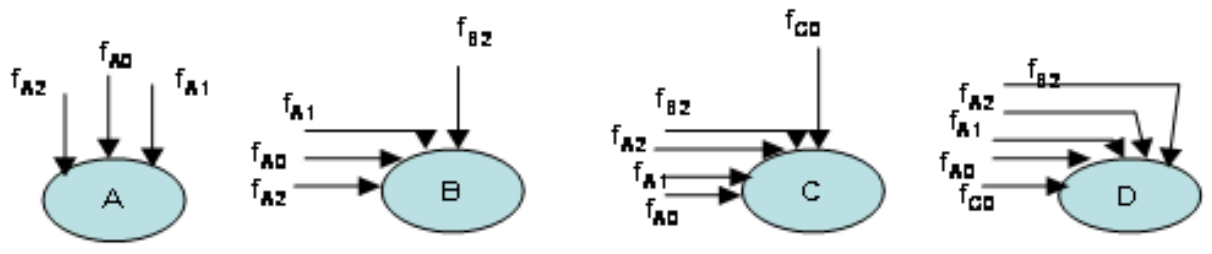

Figure: 4 : Simple multihop scenario with different flows.

Referring to above Figure:4, suppose a node A generates voice, video and data packets which belongs to the priority level 2,1 and 0 in accordance with the proposed protocol. Let the individual flows be named as $\mathrm{f}_{\mathrm{A} 2}, \mathrm{f}_{\mathrm{A} 1}$ and $\mathrm{f}_{\mathrm{A} 0}$. The packets are enqued in its own prioritized queue. Node ' $\mathrm{B}$ ' generates voice packets belonging to the priority level 2 and let it be designated by flow ID $\mathrm{f}_{\mathrm{B} 2}$. This node ' $\mathrm{B}$ ' not only have to transmit from its own $\mathrm{f}_{\mathrm{B} 2}$, but also forward the packets of $\mathrm{f}_{\mathrm{A} 2}, \mathrm{f}_{\mathrm{A} 1}$ and $\mathrm{f}_{\mathrm{A} 0}$. Node ' $\mathrm{C}$ ' generates data packets which belongs to the priority level ' 0 ' and let the flow ID be set as $\mathrm{f}_{\mathrm{C} 0}$. The node ' $\mathrm{C}$ ' forwards the packets of flows $\mathrm{f}_{\mathrm{B} 2}, \mathrm{f}_{\mathrm{A} 2}, \mathrm{f}_{\mathrm{A} 1}$ and $\mathrm{f}_{\mathrm{A} 0}$ also transmits the packets from its own $\mathrm{f}_{\mathrm{C} 0}$. Initially all the flows $\mathrm{f}_{\mathrm{B} 2}, \mathrm{f}_{\mathrm{A} 2}$ $, \mathrm{f}_{\mathrm{A} 1}, \mathrm{f}_{\mathrm{A} 0}$ and $\mathrm{f}_{\mathrm{C} 0}$ service obtained by the flow (serv_flow) equals to 1 . That means, serv $\mathrm{f}_{\mathrm{B} 2}=1$, serv_ $\mathrm{f}_{\mathrm{A} 2}=1, \operatorname{serv}_{-} \mathrm{f}_{\mathrm{A} 1}=1, \operatorname{serv}_{-} \mathrm{f}_{\mathrm{A} 0}=1$ and serv $\mathrm{f}_{\mathrm{C} 0}=1$. Let node ' $\mathrm{A}$ ' simultaneously have voice, video and data packets to transmit. According to the rule the packets belonging to the priority 2 will be dequed and node 'A' will contend to access the channel with CWmin, CWmax belonging to the priority 2 . If the node becomes successful in accessing the channel and send the packets which consequently reach its intended destination ' $D$ ' then ' $D$ ' increment serv_ $f_{A 2}$ by 1 that is equal to 1 . This information is piggybacked in the ACK packet and send to the downstream nodes (towards source). When node ' $C$ ' receives the $A C K$, it set serv_f $f_{A 2}=2$; The node $\mathrm{B}$ and hence node $\mathrm{A}$ also set their serv $\mathrm{f}_{\mathrm{A} 2}=2$ on receiving the $\mathrm{ACK}$.

Now node ' $B$ ' suppose want to transmit its own voice packets belonging to the flow $f_{B 2}$ at the same time node ' $A$ ' wants to transmit the packet belonging to $f_{A 2}$. As serv_f $f_{A 2}=2$ and serv_ $f_{B 2}=1$ at $B$, the packets belonging to the less served flow that is $f_{B 2}$ will be dequed.Node ' $\mathrm{B}$ ' will contend for accessing the channel with contention window size with the scaling factor 0.5 where as node A will contend with the scaling factor 1 . That means the node B will contend for the channel with less sized window as compared to node A .Hence node B will be in a better position to access the channel. Hence the packets belonging to a less served flow such as serv_ $f_{B 2}$ will be transmitted thereby showing the fairness.

\section{ANALYTICAL MODEL}

In this paper, we have assumed that there are ' $n$ ' active stations in the network. Each station has implemented 3 queues of priority level 2, 1 and 0 .Hence there are total ' $n * 3$ ' queue entities. This is equivalent to ' $3 * \mathrm{n}$ ' stations in the legacy IEEE 802.11 DCF. 
Further let it be assumed that any queue in any station has packets ready to send. Table: 1 may be referred for the symbol and expression used here.

Table: 1: Symbols used in the analysis

\begin{tabular}{|c|c|c|c|c|c|}
\hline $\begin{array}{l}\text { Sl. } \\
\text { No }\end{array}$ & Parameters & Description & $\begin{array}{l}\text { Sl. } \\
\text { No }\end{array}$ & Parameters & Description \\
\hline 1 & $\mathrm{P}_{\mathrm{c}}$ & Collision probabilty & 16 & $\mathrm{~T}_{\text {DIFS }}$ & DIFS period \\
\hline 2. & $\mathrm{P}_{\mathrm{b}}$ & Busy Probability & 17 & $£$ & Propagation delay \\
\hline 3. & $\zeta_{\mathrm{i}}$ & $\begin{array}{l}\text { Transmission } \\
\text { probability }\end{array}$ & 18 & $\mathrm{~N}_{\mathrm{c}, \mathrm{i}}$ & $\begin{array}{l}\text { Random variable representing } \\
\text { the number of collisions before } \\
\text { transmitting a frame }\end{array}$ \\
\hline 4 & $\mathrm{P}_{\mathrm{s}, \mathrm{i}}$ & Success Probability & 19 & $\mathrm{X}_{\mathrm{i}}$ & $\begin{array}{l}\text { Random variable representing } \\
\text { the time interval during which } \\
\text { the counter reaches zero without } \\
\text { considering the case when the } \\
\text { counter freezes }\end{array}$ \\
\hline 5 & $\mathrm{~S}_{\mathrm{i}}$ & $\begin{array}{l}\text { Normalized } \\
\text { throughput }\end{array}$ & 20 & $\mathrm{~F}_{\mathrm{i}}$ & $\begin{array}{l}\text { Time duration that the backoff } \\
\text { counter of a station freezes }\end{array}$ \\
\hline 6 & $\mathrm{E}[\mathrm{P}]$ & $\begin{array}{l}\text { Average packet } \\
\text { payload size }\end{array}$ & 21 & $\mathrm{~N}_{\mathrm{Fi}}$ & $\begin{array}{l}\text { The number of time that the } \\
\text { backoff counter freezes }\end{array}$ \\
\hline 7 & $\mathrm{n}_{\mathrm{i}}$ & No. of station & 22 & $\mathrm{~B}_{\mathrm{i}}$ & $\begin{array}{l}\text { Backoff delay of a station for the } \\
\text { priority class 'i' }\end{array}$ \\
\hline 8 & $\sigma$ & Slot duration & 23 & $\mathrm{D}_{\mathrm{i}}$ & $\begin{array}{l}\text { Random variable representing } \\
\text { the frame delay }\end{array}$ \\
\hline 9 & $\mathrm{~T}_{\mathrm{s}, \mathrm{i}}$ & $\begin{array}{l}\text { Successful } \\
\text { transmission time }\end{array}$ & 24 & $\mathrm{~T}_{0}$ & $\begin{array}{l}\text { Time duration after collision } \\
\text { that a station has to wait before } \\
\text { sensing the channel again }\end{array}$ \\
\hline 10 & $\mathrm{~T}_{\mathrm{c}, \mathrm{i}}$ & Average collision & 25 & $\mathrm{~T}_{\text {timeou }}$ & Duration of the ACK \\
\hline 11 & $\mathrm{~T}_{\mathrm{H}}$ & $\begin{array}{l}\text { Header tx time ( both } \\
\text { PHY and MAC ) }\end{array}$ & & & \\
\hline 12 & $\mathrm{~T}_{\mathrm{E}[\mathrm{P}]}$ & Payload tx Time & & & \\
\hline 13 & $\mathrm{~T}_{\mathrm{E}[\mathrm{P} *]}$ & $\begin{array}{l}T E[P] \text { for longest } \\
\text { frame }\end{array}$ & & & \\
\hline 14 & $\mathrm{~T}_{\mathrm{ACK}}$ & $\begin{array}{l}\text { Time to transmit the } \\
\text { ACK }\end{array}$ & & & \\
\hline 15 & $\mathrm{~T}_{\text {SIFS }}$ & SIFS period & & & \\
\hline
\end{tabular}

Assuming $\mathrm{P}_{\mathrm{c}}$ and $\mathrm{P}_{\mathrm{b}}$ are both constant and independent, then in accordance with Bianchi's model [20] the bidirectional random process $\{\mathrm{s}(\mathrm{i}, \mathrm{t}), \mathrm{b}(\mathrm{i}, \mathrm{t})\}$ is discrete-time Markov chain and is depicted in the following Figure 5 .The state of each station in the priority class ' $\mathrm{i}$ ' is described by $\{\mathrm{i}, \mathrm{j}, \mathrm{k}\}$. 


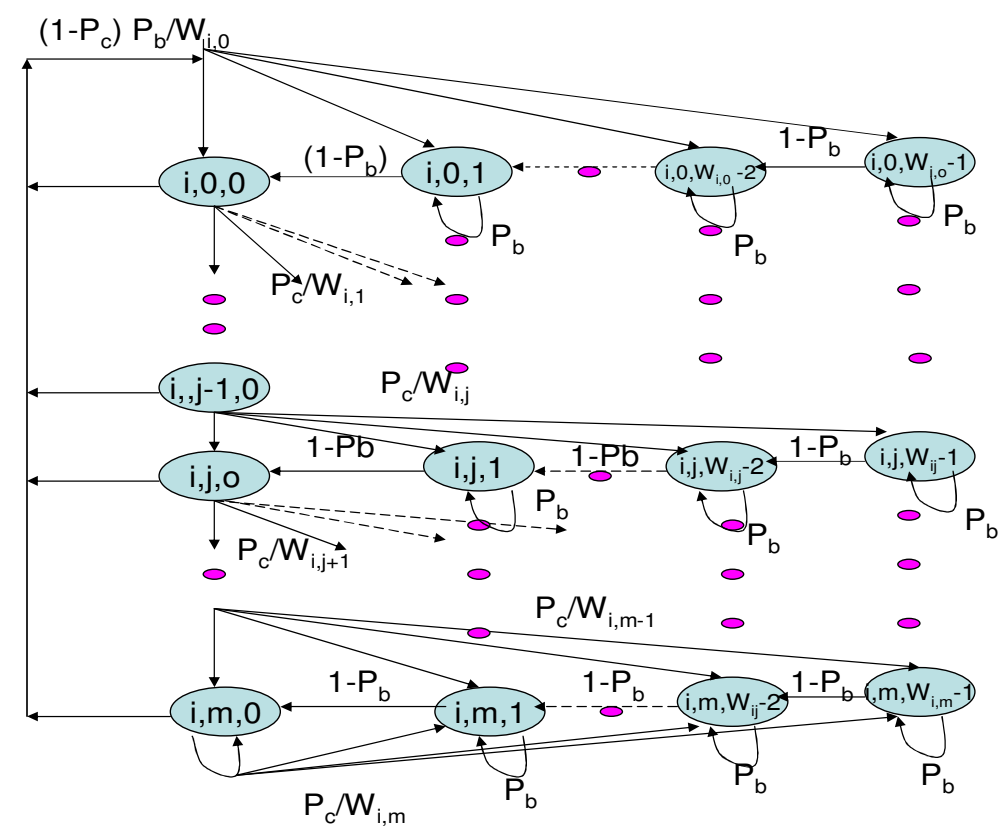

Fig 4: The state transition diagram for the priority class "i"

In accordance with the above Markov Model, the non -null one step transition probabilities are

$$
\mathrm{P}\{(\mathrm{i}, \mathrm{j}, \mathrm{k}) \mid(\mathrm{i}, \mathrm{j}, \mathrm{k})\}=\mathrm{P}_{\mathrm{b}} \text { for } 1 \leq \mathrm{k} \leq \mathrm{W}_{\mathrm{i}, \mathrm{j}}-1 \& 0 \leq \mathrm{j} \leq \mathrm{m}
$$

The above expression indicates that the channel is busy and hence there is no decrement in the backoff counter.

$$
\mathrm{P}\{(\mathrm{i}, \mathrm{j}, \mathrm{k}) \mid(\mathrm{i}, \mathrm{j}, \mathrm{k}+1)\}=1-\mathrm{P}_{\mathrm{b}} \text { for } 0 \leq \mathrm{k} \leq \mathrm{W}_{\mathrm{i}, \mathrm{j}}-2 \quad \& \text { and } 0 \leq \mathrm{j} \leq \mathrm{m}
$$

This indicates that the channel is free and hence backoff counter is decremented by 1 .

$$
\mathrm{P}\left\{(\mathrm{i}, 0, \mathrm{k}) \mid(\mathrm{i}, \mathrm{j}, 0\}=\left(1-\mathrm{P}_{\mathrm{c}}\right) * \mathrm{P}_{\mathrm{b}} / \mathrm{W}_{\mathrm{i}, 0} \quad \text { for } 0 \leq \mathrm{k} \leq \mathrm{W}_{\mathrm{i}, 0}-1 \text { and } 0 \leq \mathrm{j} \leq \mathrm{m}\right.
$$

The above expression account for the fact that a new packet following a successful packet transmission starts with backoff stage ' 0 ' for the priority class ' $i$ ' and the backoff is initially chosen in the range $\left(0, \mathrm{~W}_{\mathrm{i}, 0}-1\right)$.

$\mathrm{P}\left\{(\mathrm{i}, \mathrm{j}, \mathrm{k}) \mid(\mathrm{i}, \mathrm{j}-1,0\}=\mathrm{P}_{\mathrm{c}} / \mathrm{W}_{\mathrm{i}, \mathrm{j}} \quad\right.$ for $0 \leq \mathrm{k} \leq \mathrm{W}_{\mathrm{i}, \mathrm{j}}-1$ and $1 \leq \mathrm{j} \leq \mathrm{m}$

The above expression models the system after unsuccessful transmission.

$$
\mathrm{P}\left\{(\mathrm{i}, \mathrm{m}, \mathrm{k}) \mid(\mathrm{i}, \mathrm{m}, 0\}=\mathrm{P}_{\mathrm{c}} / \mathrm{W}_{\mathrm{i}, \mathrm{m}} \quad \text { for } 0 \leq \mathrm{k} \leq \mathrm{W}_{\mathrm{i}, \mathrm{m}}-1\right.
$$

Let $b_{i, j, k}-\operatorname{limin}_{t \rightarrow \infty} \mathrm{P}[\mathrm{s}(\mathrm{i}, \mathrm{l})-\mathrm{j}, \mathrm{b}(\mathrm{i}, \mathrm{l})-\mathrm{k}\}$;

where $0 \leq \mathrm{j} \leq \mathrm{m}$ and $0 \leq \mathrm{k} \leq \mathrm{W}_{\mathrm{i}, \mathrm{j}}-1 \quad--(6)$

be the stationary distribution of the Markov Chain .

In steady state the following relations can be derived through chain regularities.

$$
\mathrm{b}_{\mathrm{i}, \mathrm{j}, 0}=\mathrm{P}_{\mathrm{c}}^{\mathrm{j}} * \mathrm{~b}_{\mathrm{i}, 0,0} \text { where } 0 \leq \mathrm{j} \leq \mathrm{m}-1
$$




$$
\begin{aligned}
& \mathrm{b}_{\mathrm{i}, \mathrm{m}, 0}=\mathrm{P}_{\mathrm{c}}^{\mathrm{m}} * \mathrm{~b}_{\mathrm{i}, 0,0} /\left(1-\mathrm{P}_{\mathrm{c}}\right) \text { where } \mathrm{j}=\mathrm{m} \\
& \mathrm{b}_{\mathrm{i}, \mathrm{j}, \mathrm{k}}=\left\{\left(\mathrm{W}_{\mathrm{i}, \mathrm{j}}-\mathrm{k}\right) / \mathrm{W}_{\mathrm{i}, \mathrm{j}}\right\} *\left\{1 /\left(1-\mathrm{P}_{\mathrm{b}}\right)\right\} * \mathrm{~b}_{\mathrm{i}, \mathrm{j}, 0} \\
& \text { Where } 0 \leq \mathrm{j} \leq \mathrm{m} \text { and } 1 \leq \mathrm{k} \leq \mathrm{W}_{\mathrm{i}, \mathrm{j}}-1
\end{aligned}
$$

By applying normalized condition $\mathrm{b}_{\mathrm{i}, 0,0}$ can be determined as follows:

$$
1=\sum_{j=0}^{m} \Sigma_{k=0}^{W_{i j}-1} b_{i, j, k}
$$

Now plugging (7) to (9) in (10), We have,

$$
\begin{aligned}
1 & =\sum_{j=0}^{m} \sum_{k=0}^{W_{i, j}-1} b_{i, j, k} \\
& =\sum_{j=0}^{m} b_{i, j, 0} \sum_{k=2}^{W_{i j}-1}\left\{\left(W_{i j}-k\right) / W_{i j}\right) *\left\{1 /\left(1-P_{b}\right)\right\} \\
& =\left\{1 /\left(1-P_{b}\right)\right\} \sum_{i=0}^{m}\left\{b_{i, j, 0}\left(W_{i, j}+1\right) / 2\right\} \\
& =\left\{\frac{1}{1-P_{b}}\right\} * b_{i, 0,0} / 2\left[W_{i}\left(\sum_{j=0}^{m-1}\left(2 P_{0}\right)+\frac{\left(2 P_{c}\right)^{m}}{--P_{c}}+\frac{1}{1-P_{c}}\right]\right.
\end{aligned}
$$

From the above equation we can get the value of $b_{i, 0,0}$ as follows.

$$
\mathrm{b}_{\mathrm{i}, 0,0}=2\left(1-\mathrm{P}_{\mathrm{b}}\right)\left(1-2 \mathrm{P}_{\mathrm{c}}\right)\left(1-\mathrm{P}_{\mathrm{c}}\right) /\left\{\left(1-2 \mathrm{P}_{\mathrm{c}}\right)\left(\mathrm{W}_{\mathrm{i}}+1\right)+\mathrm{P}_{\mathrm{c}} \mathrm{W}_{\mathrm{i}}\left(1-\left(2 \mathrm{P}_{\mathrm{c}}\right)^{\mathrm{m}}\right\}\right.
$$

Now,

$$
\begin{gathered}
\zeta_{\mathrm{i}}=\sum_{\mathrm{i}-0}^{\mathrm{m}} b_{i, j, 0}=b_{i, 0,0} /\left(1-P_{o}\right) \\
=2\left(1-\mathrm{P}_{\mathrm{b}}\right)\left(1-2 \mathrm{P}_{\mathrm{c}}\right) /\left\{\left(1-2 \mathrm{P}_{\mathrm{c}}\right)\left(\mathrm{W}_{\mathrm{i}}+1\right)+\mathrm{P}_{\mathrm{c}} \mathrm{W}_{\mathrm{i}}\left(1-\left(2 \mathrm{P}_{\mathrm{c}}\right)^{\mathrm{m}}\right\}\right. \\
P_{b}=1-\prod_{h=\mathrm{d}}^{3}\left(1-\zeta_{\mathrm{i}}\right)^{\mathrm{nh}} \\
P_{c}=1-\left[\prod_{h=0}^{i-1}\left(1-\zeta_{\mathrm{h}}\right)^{\mathrm{nh}}\right]\left(1-\zeta_{\mathrm{i}}\right)^{\mathrm{ni}-1}\left[\prod_{i+3}^{3}\left(1-\zeta_{\mathrm{h}}\right)^{\mathrm{nh}}\right]
\end{gathered}
$$

Saturation Throughput

Saturation throughput is the maximum limit of the throughput that the system can carry in stable condition. In several access mechanisms the throughput increases with the offered load .It increases to a maximum value called maximum throughput and then starts decreasing as the offered load increases further. This causes in the practical impossibility to operate the random access scheme at its maximum throughput for a long period time. Hence it is meaningless to take the maximum throughput as the performance figure and hence saturation throughput is taken for performance measurement [22].

The probability with which a packet belonging to priority class ' $i$ ' is transmitted is given by

$$
\begin{aligned}
P_{z i} & -z_{i} \zeta_{\mathrm{i}}\left(1-\zeta_{\mathrm{i}}\right)^{\mathrm{n}-1} \prod_{h=h h=i}^{\mathrm{R}}\left(1-\zeta_{\mathrm{h}}\right)^{\mathrm{nh}} \\
& =\mathrm{n}_{\mathrm{i}} \zeta_{\mathrm{i}} /\left(1-\zeta_{\mathrm{i}}\right)\left(1-\mathrm{P}_{\mathrm{b}}\right)
\end{aligned}
$$
given by

In accordance with Bianchi [19] the normalized throughput for priority class ' $\mathrm{i}$ ' is

$\mathrm{S}_{\mathrm{i}}=\mathrm{E}$ [payload information transmitted in a slot time for the priority i class] / E [ length of a slot time ]

$$
\begin{array}{ll}
= & \mathrm{P}_{\mathrm{s}, \mathrm{i}} \mathrm{E}[\mathrm{P}] /\left(1-\mathrm{P}_{\mathrm{b}}\right) \sigma+\mathrm{P}_{\mathrm{s}, \mathrm{i}} \mathrm{T}_{\mathrm{s}, \mathrm{i}}+\left[\mathrm{P}_{\mathrm{b}}-\mathrm{P}_{\mathrm{s}, \mathrm{i}}\right] \mathrm{T}_{\mathrm{c}, \mathrm{i}} \\
\text { where, } & \mathrm{T}_{\mathrm{s}, \mathrm{i}}=\mathrm{T}_{\mathrm{H}}+\mathrm{T}_{\mathrm{E}[\mathrm{P}]}+\mathrm{T}_{\mathrm{SIFS}}+£+\mathrm{T}_{\mathrm{ACK}}+\mathrm{T}_{\mathrm{DIFS}}+£
\end{array}
$$




$$
\mathrm{T}_{\mathrm{c}, \mathrm{i}}=\mathrm{T}_{\mathrm{H}}+\mathrm{T}_{\mathrm{E}[\mathrm{P} *]}+\mathrm{T}_{\mathrm{DIFS}}+£
$$

\section{SATURATION DELAY}

Saturation delay is the delay calculated in stable condition.

Average delay experienced by the frame $\left(\mathrm{E}\left(\mathrm{D}_{\mathrm{i}}\right)\right)=$ average time period for which the channel was busy + average backoff period+average time consumed while it experienced number of collision

\section{Average backoff period: $\left(E\left(B_{i}\right)\right.$}

Average backoff period, $\mathrm{E}\left(\mathrm{B}_{\mathrm{i}}\right)$, can calculated as the sum of average time period taken by the counter to be decremented to zero without considering the case when the counter freezes $\left(\mathrm{E}\left(\mathrm{X}_{\mathrm{i}}\right)\right.$ ) and average time duration for which the station freezes before transmitting the frame $\left(\mathrm{E}\left(\mathrm{F}_{\mathrm{i}}\right)\right)$

Mathematically

$$
\begin{gathered}
\mathrm{E}\left(\mathrm{B}_{\mathrm{i}}\right)=\mathrm{E}\left(\mathrm{X}_{\mathrm{i}}\right)+\mathrm{E}\left(\mathrm{F}_{\mathrm{i}}\right) \\
\text { Where }, E\left(X_{!}\right)=\sum_{j=0}^{m} \sum_{k=1}^{W_{i, j}} k \cdot b_{i, j k} \\
=\left\{\mathrm{b}_{\mathrm{i}, 0,0} / 6\left(1-\mathrm{P}_{\mathrm{b}}\right)\right\}\left\{\left(\mathrm{W}_{\mathrm{i}, 0}^{2}\left(1-\mathrm{P}_{\mathrm{c}}-3 \mathrm{P}_{\mathrm{c}}\left(4 \mathrm{P}_{\mathrm{c}}\right)^{\mathrm{m}}\right)+4 \mathrm{P}_{\mathrm{c}}-1\right) /\left(1-4 \mathrm{P}_{\mathrm{c}}\right)\left(1-\mathrm{P}_{\mathrm{c}}\right)\right\}
\end{gathered}
$$

And $\mathrm{E}\left(\mathrm{F}_{\mathrm{i}}\right)=\mathrm{E}\left(\mathrm{N}_{\mathrm{Fi}}\right)\left[\left(\mathrm{P}_{\mathrm{s}, \mathrm{i}} / \mathrm{P}_{\mathrm{b}}\right) * \mathrm{~T}_{\mathrm{s}, \mathrm{i}}+\left(1-\left(\mathrm{P}_{\mathrm{s}, \mathrm{I}} / \mathrm{P}_{\mathrm{b}}\right) * \mathrm{~T}_{\mathrm{c}, \mathrm{i}}\right]--\right.$

Hence, Saturation delay and hence the equation (20) can be expressed by

$$
\mathrm{E}\left(\mathrm{D}_{\mathrm{i}}\right)=\mathrm{E}\left(\mathrm{N}_{\mathrm{c}, \mathrm{i}}\right)\left[\mathrm{E}\left(\mathrm{B}_{\mathrm{i}}\right)+\mathrm{T}_{\mathrm{c}, \mathrm{i}}+\mathrm{T}_{0}\right]+\mathrm{E}\left(\mathrm{B}_{\mathrm{i}}\right)+\mathrm{T}_{\mathrm{s}, \mathrm{i}}
$$

\section{PERFORMANCE EVALUATION}

Where $\mathrm{T}_{0}=\mathrm{T}_{\text {SIFS }}+\mathrm{T}_{\text {timeout }}$.

In order to evaluate the protocol three different type of traffic is used. The voice traffic is assigned with highest priority 2.The video traffic is assigned the priority level 1 and the least priority level 'o' is assigned to the datagram traffic. Voice traffic usually considered as a service with CBR traffic. The data bit rate of the voice traffic is taken to be $64 \mathrm{kbps}$.Video traffic is usually modeled as variable bit rate traffic. Continuous bit stream is generated for a certain holding period. The bit rate of different states is obtained from a truncated exponential distribution with minimum and maximum bit rate values. The holding times of the state are assumed to be statistically independent and exponentially distributed. The following table gives the numerical values for the video traffic which were taken for the analysis.

Table: 2 : Numerical values for video traffic model

\begin{tabular}{|l|l|}
\hline PARAMETER & VALUE \\
\hline Peak Bit Rate(PBR) & $420 \mathrm{kbps}$ \\
\hline Average Bit Rate (ABR) & $240 \mathrm{kbps}$ \\
\hline Minimum Bit Rate(MBR) & $120 \mathrm{kbps}$ \\
\hline Maximum Packet Delay & $75 \mathrm{~ms}$ \\
\hline
\end{tabular}


It is assumed that the data traffic arrive at each station following a poisson process with the mean value of $\lambda$. According to the traffic model defined above, the traffic parameters used for evaluating our protocol is listed in the following Table.3.

Table:3: The parameters are for the $2 \mathrm{Mbps}$ channel rate.

\begin{tabular}{|l|l|l|l|}
\hline Sl. No. & Parameter & Symbol & Value (in $\mu \mathrm{s})$ \\
\hline 1. & Slot time & $\mathrm{T}_{\text {slot }}$ & 20 \\
\hline 2. & Propagation delay & $£$ & 1 \\
\hline 3. & $\begin{array}{l}\text { Transmission time for physical } \\
\text { pramble }\end{array}$ & $\mathrm{T}_{\text {preamble }}$ & 72 \\
\hline 4. & DIFS period & $\mathrm{T}_{\text {DIFS }}$ & 50 \\
\hline 5. & SIFS period & $\mathrm{T}_{\text {SIFS }}$ & 10 \\
\hline 6. & Time to transmit physical header & $\mathrm{T}_{\mathrm{PHH}}$ & 24 \\
\hline 7. & Transmission time for MAC header & $\mathrm{T}_{\mathrm{MACH}}$ & 136 \\
\hline 8. & Transmission time for ACK & $\mathrm{T}_{\mathrm{ACK}}$ & 152 \\
\hline
\end{tabular}

\section{Performance Metrics:}

A. Transmission Delays: The time elapsed between the instant the source transmits the packet $\&$ the instant the destination node receives it.

\section{B. Saturation Throughput}

Saturation throughput is the maximum limit of the throughput that the system can carry in stable condition. In several access mechanisms the throughput increases with the offered load .It increases to a maximum value called maximum throughput and then starts decreasing as the offered load increases further. This causes in the practical impossibility to operate the random access scheme at its maximum throughput for a long period time. Hence it is meaningless to take the maximum throughput as the performance figure and hence saturation throughput is taken for performance measurement. In this section the saturation throughput and delay obtained through analysis are given. In order to simplify the analysis it is assumed that the channel is error free and become corrupted when collision occurs.

\section{RESULTS}

Analysis is carried out here for three scenarios. Scenario_1 have 6 nodes, where number of nodes having voice, video and data traffic is 3, 2 and 1 respectively. Scenario_2 have 14 nodes out of which 7,5,2 are voice, video and data nodes. In Scenario_3, there are 15,10,5 nodes are with voice, video and data traffic respectively. The channel rate was taken to be $2 \mathrm{Mbps}$. Table I shows $\mathrm{T}_{\mathrm{E}[\mathrm{P}]}$ values. 
International Journal of Wireless \& Mobile Networks (IJWMN) Vol. 3, No. 2, April 2011

Table.3: Transmission time of payloads under $2 \mathrm{Mbps}$

\begin{tabular}{|l|l|}
\hline $\begin{array}{l}\mathrm{T}_{\mathrm{E}[\mathrm{P} 2]}: \text { Time for pay load } \\
\text { transmission(voice: cbr) }\end{array}$ & $800 \mu \mathrm{s}$ \\
\hline $\begin{array}{l}\mathrm{T}_{\mathrm{E}[\mathrm{P} 1] \mathrm{PBR}}: \text { Time for pay load transmission } \\
\text { (video: } \mathrm{PBR})\end{array}$ & $\begin{array}{l}15750 \\
\mu \mathrm{s}\end{array}$ \\
\hline $\begin{array}{l}\mathrm{T}_{\mathrm{E}[\mathrm{P} 1] \mathrm{MBR}}: \text { Time for pay load transmission } \\
\text { (video:MBR) }\end{array}$ & $4500 \mu \mathrm{s}$ \\
\hline $\begin{array}{l}\mathrm{T}_{\mathrm{E}[\mathrm{P} 1] \mathrm{ABR}}: \mathrm{Time} \text { for pay load transmission } \\
\text { (video: } \mathrm{ABR} \text { ) }\end{array}$ & $9000 \mu \mathrm{s}$ \\
\hline $\mathrm{T}_{\mathrm{E}[\mathrm{P} 0]}: \mathrm{Time}$ for pay load transmission & $4092 \mu \mathrm{s}$ \\
(data) & \\
\hline
\end{tabular}

Table:4: Saturated Throughput for Voice Traffic(S2).

\begin{tabular}{|l|l|}
\hline Scenarios & Values of S2 \\
\hline Scenario_1 & 0.6875 \\
\hline Scenario_2 & 0.2067 \\
\hline Scenario_3 & 0.052 \\
\hline
\end{tabular}

Table:5: Saturation throughput for Video Traffic (S1)

\begin{tabular}{|c|c|c|c|}
\hline & Peak bit rate(PBR) & Minimum bit rate(MBR) & Average bit rate(ABR) \\
\hline Scenario_1 & 0.304 & 0.091 & 0.1785 \\
\hline Scenario_2 & 0.096 & 0.027823 & 0.055549 \\
\hline Scenario_3 & 0.0023 & 0.0006641 & 0.0013282 \\
\hline
\end{tabular}

Table:6:Saturation Throughput for Datagram Traffic(S0)

\begin{tabular}{|l|l|}
\hline Scenarios & Values of S0 \\
\hline Scenario_1 & 0.071 \\
\hline Scenario_2 & 0.0182 \\
\hline Scenario_3 & 0.00055 \\
\hline
\end{tabular}


Table 4, 5 and 6 shows the calculated value of saturation throughput for different traffic categories \& scenarios. It may be observed from the table that the throughput decreases with number of nodes \& with less prioritized traffics. It is shown in Figure $6 \& 7$.

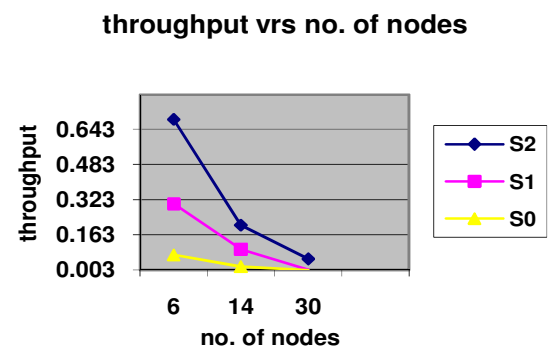

Figure:6: Throuput Vrs Number of nodes

\section{Saturation throughput for different priority class}

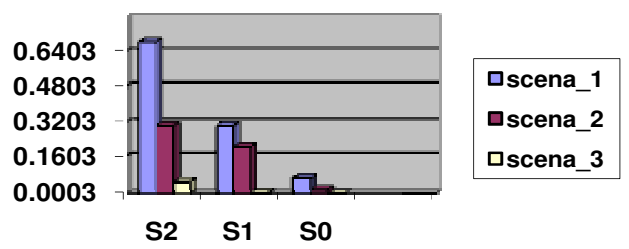

Figure:7: Saturation Throughput for different Priority Class.

The calculated values of transmission probabilities for different priority classes $\left(\zeta_{0}, \zeta_{1}, \zeta_{2}\right)$ are tabulated in Table 7. It may be observed that the values decrease with traffic categories and also with number of nodes. The variation of saturation throughput with respect to transmission probabilities shown in Fig.7,8 and 9.

Table: 7: Transmission Probabilities for different Traffic categories.

\begin{tabular}{|l|l|l|l|}
\hline SCENARIOS & $\zeta_{2}$ & $\zeta_{1}$ & $\zeta_{0}$ \\
\hline Scenario_1 & 0.0955 & 0.04775 & 0.024 \\
\hline Scenario_2 & 0.026 & 0.013 & 0.0065 \\
\hline Scenario_3 & 0.002 & 0.001 & 0.0005 \\
\hline
\end{tabular}




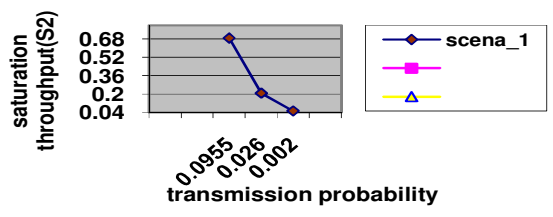

Figure:7: Transmission Probability Vrs Saturation Throughput for Voice Traffic

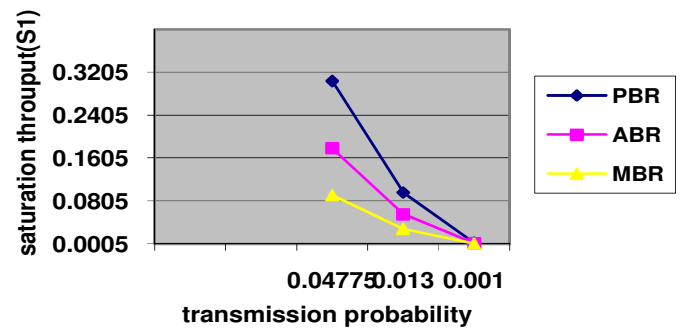

Figure:8:Transmission Probability Vrs Saturation Throughput for Video Traffic

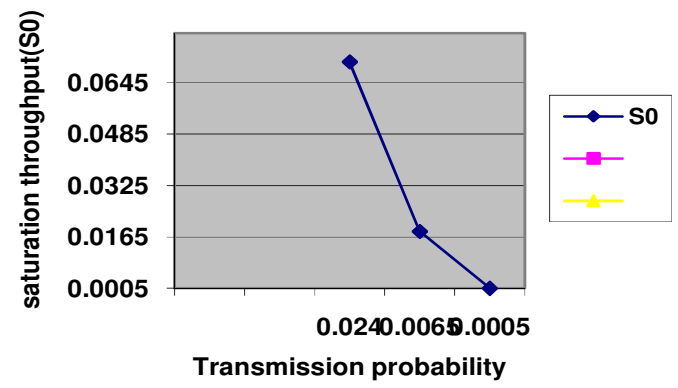

Figure:9:Transmission Probability Vrs Saturation Throughput for Data Traffic.

The delay experienced by various traffic categories voice, video and data is shown in the Table: 8. Here D2, D1 \& D0 are the delays in ms experienced by Voice, Video \& Data traffics respectively. The high priority traffic which is time sensitive is experiencing fewer delays. Delay increases for low priority traffic. The high priority traffic also experiences much delay when the number of nodes in the network increases.Figure:10: shows the delay variation for different priority classes with respect to node density. Delay increases at a slower rate with increase in node density in case of a high priority traffic such as voice where as it increases sharply for low priority traffic such as data. 
Table:8: Delays experienced by different priority traffics.

\begin{tabular}{|c|c|c|c|}
\hline Scenarios & D2 & D1 & D0 \\
\hline Scenario_1 & 7.89 & 12.566 & 59.720 \\
\hline Scenario_2 & 21.041 & 42.036 & 219.671 \\
\hline Scenario_3 & 60.491 & 106.016 & 583.196 \\
\hline
\end{tabular}

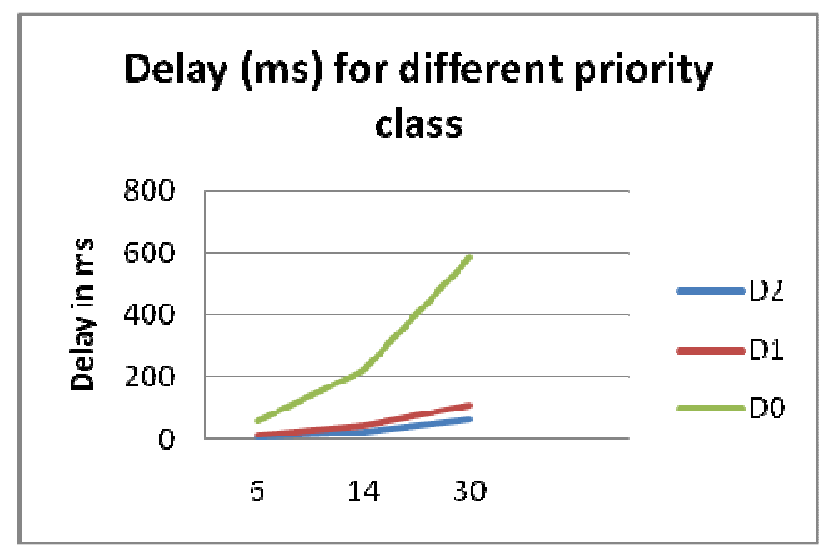

Figure:10: Delay experienced by different prioritized Traffic

\section{CONCLUSION}

In this paper, a medium access control protocol has been proposed for adhoc network. The protocol supports quality of service, exhibits fairness over multihop adhoc network. Throughput and delay experienced by different type of traffics were also analyzed. It was found that the high prioritized traffics have high throughput and experienced less delay as compared to the low prioritized traffics. Hence time sensitive traffics may be assigned high priority and its delay and bandwidth requirement may be served qualitatively. Although, Quality of Service assured protocol has been proposed in this paper, there are some works still to be addressed. In this paper, channel is assumed to be ideal. Hence the working of the protocol under noisy condition may need to be studied. As in Mobile Adhoc Network (MANET), any node may join or leave at any instant of time. Hence the topology of the network changes dynamically. The working of the protocol under such condition still remains to be explored. 
International Journal of Wireless \& Mobile Networks (IJWMN) Vol. 3, No. 2, April 2011

\section{REFERENCES}

[1]. H.Y. Hsieh, R.sivakumar, performances comparison of cellular and multihop wireless networks: A quantitive study .- in proceedings of ACM SIGMETRICS, Boston, MA,USA June 2001.

[2]. IEEE, "Wireless LAN medium access control (MAC) and physical layer (PHY) specification," IEEE Std. 802.11, June 1999.

[3]. Shiann-Tsong Sheu and Tzu-Fang Sheu, "DBASE:A Distributed Bandwidth Allocation/Sharing / Extension Protocol for Multimedia over IEEE 802.11 Ad Hoc Wireless LAN," IEEE INFOCOM 2001.

[4]. J. L. Sobrinho and A. S. Krishnakumar, "Quality-of-Service in Ad Hoc Carrier Sense Multiple Access Networks," IEEE Journal on Selected Areas in Communications, 17(8):1353-1368, Aug. 1999.

[5]. A. Veres, A. T. Campbell, M. Barry, and L. Sun, "Supporting Service Differentiation in Wireless Packet Networks Using Distributed Control," IEEE Journal on Selected Area in Communication, 19(10):2081-2093,Oct. 2001.

[6]. Zhou Ying, A.L. Anand and L.jacob “ A QoS Enabled MAC protocol for Multihop Adhoc Wireless Networks"IEEE international conference on performance , computing and communication“9-11 April 2003 pp 149-156.

[7]. Benveniste, M., 'Tiered contention multiple access' (TCMA), a QoS-based distributed MAC protocol 'The 13th IEEE International Symposium on Personal, Indoor and Mobile Radio Communications, Volume: 2 , 15-18 Sept. 2002 Pages:598 - 604 vol.2.

[8]. J. Sobrinho and A. Krishnakumar, "Real-time traffic over the ieee802.11 medium access control layer," in Bell Labs Technical Journal, 1996, pp. 172-187.

[9]. S. Mangold, S. Choi, P. May, O. Klein, G. Hiertz, and L. Stibor,"IEEE 802.11e wireless lan for quality of service (invited paper)," in Proceedings of the European Wireless, vol. 1, Florence, Italy,

Feb. 2002,pp. 32-39.

[10]. N. H. Vaidya, P. Bahl, and S. Gupta, "Distributed Fair Scheduling in a Wireless LAN," MobiCom 2000, pp. 167-178

[11]. T.Nandagopal, T.E.Kim, X.Gao, and V. Bharghavan, "Achieving MAC Layer Fairness in Wireless Packet Networks," MobiCom 2000,pp. 87-98.

[12]. A.Dugar \& N.Vaidya "Priority and fair scheduling in WLAN" IEEE - MILCOM 2001 page 993-997 vol.2.

[13]. P. Gupta and P. R. Kumar, The Capacity of Wireless Networks, IEEE Transaactions on Information Theory, Vol 46, pp 388-404, March 2000.

[14]. S. Xu and T. Saadawi, "Does the IEEE 802.11 MAC Protocol Work Well in Multihop Wirelles Ad Hoc Networks?" IEEE Communications Magazine, June 2001.

[15]. G.Holland, N.Vaidya and P.Bahl “ A Rate -adaptive MAC protocol for Multihop wireless Networks” ACM/IEEE Conference on Mobile Computing and Networking (MOBICOM'01), Rome, Italy, July 2001.

[16]. D. Raguin, M. Kubisch, H. Karl, A. Wolisz “Queue-driven cut-through medium access in wireless adhoc network In proceeding of IEEE Wireless communications and Networking conference(WCNC), Atlanta, Georgia, USA March 2004. 
International Journal of Wireless \& Mobile Networks (IJWMN) Vol. 3, No. 2, April 2011

[17]. Shugong Xu, Tarek Saadawi "Revealing the problems with 802.11 medium access control protocol in multi-hop wireless adhoc networks" in www.elsivier.com computer networks - 2002

[18]. C-K Toh, V. Vassiliou etc "MARCH : A medium access control protocol for multihop adhoc network" in the proceedings of IEEE - MILCOM'2000 22-25 Oct. 2000 Pages:512 - 516 vol.1

[19]. F. Borgonovo, A. Capone, M. Cesana, L. Fratta "ADHOC MAC: a new, flexible and reliable MAC architecture for ad-hoc networks in the proceedings of IEEE WCNC `2003”.

[20]. G. Bianchi, "Performance Analysis of the IEEE 802.11 Distributed Coordination Function," IEEE J-SAC. Vol. 18, Mar. 2000, pp. 535-547.

[21]. T. S. Ho and K. C. Chen, "Performance evaluation and enhancement of the CSMA/CA MAC protocol for 802.11 wireless LAN's", in Proc. IEEE PIMRC, Taipei, Taiwan, Oct. 1996, pp. 392-396

[22]. B. Bing, "Measured Performance of the IEEE 802.11 Wireless LAN," IEEE LCN'99

[23]. Y chen, Q.A.Zeng and D.P.Agrawal “ Performance Analysis and Enhancement for IEEE 802.11 MAC Protocol" IEEE'2003

[24]. V. Bharghavan, A. Demers, S. Shenker, and L. Zhang. "MACAW: A Media-Access Protocol for Packet Radio". In Proceedings of ACM SIGCOMM 1994.

[25] Latkoski, P., Hadi-velkov, Z., \& Popovski, B. (2006). Extended model for performance analysis of non-saturated

IEEE 802.11 DCF in erroneous channel. In Proceedings of International Conference on mobile Adhoc and Sensor Systems, 783-788.

[26] Daneshgaran, F., Laddomada, M., Mesiti, F., Mondin, M., \& Zanolo, M. (2008). Saturation throughput analysis of IEEE 802.11 in presence of non ideal transmission channel and capture effects. IEEE transactions on Communications, 56, 1178-1188.

[27] .Daneshgaran, F., Laddomada, M., Mesiti, F., \& Mondin, M. (2008). Unsaturated throughput analysis of IEEE 802.11 in presence of non ideal transmission channel and capture effects. IEEE transactions on Wireless Communications, 7, 1276-1286.

\section{Authors}

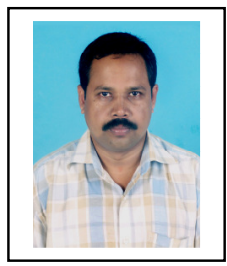

D.D.Seth is currently placed as the Associate Professor in the School of Electronics, KIIT University Bhubaneswar,India.In 1991, he received his Bachelor of Engineering degree in Electronics and Telecommunication Engineering from University College of Engineering , Burla, Orissa(India) and Master's Degree from Indian Institute of Information Technology, Allahabad with specialization- Wireless Communication and Computing in the year 2004. Previously he was also working as Senior Lecturer in Birla Institute of Technology, Mesra, Ranchi. His research interests include Mobile Adhoc Network, Wireless Sensor Network.

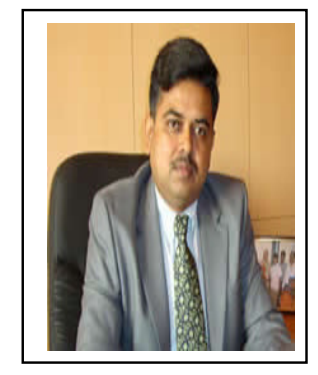

Srikanta Patnaik is Chairman of Interscience Group of Institutions,Bhubaneswar,India. Previously, he was Professor and Head of Information Technology Department, and Chairman, Post Graduate Council of F.M. University,Balasore,Orissa.He was graduated in Electronics and Communication in 1989 and post graduate in Electronics Systems and Communication in 1993 from the same institute.He has received his Ph.D in Engineering in the year 1999 from Jadavpur University, Calcutta..His active research area is Machine Intelligence and Robotics.He has published more than 60 technical papers in the national/international journals and magazines of repute.He is the invited author of the chapter entitled "Cognition Methods and Their Applications in Robotics" published by kluwer Academic Press,USA.He is also the Chief Editor of the volume on "Inovations in Machine Intelligence and Robot Perception" published by SPRINGER-VERLAG,Germany, which has been published in 2005.He is also the author of the book "Robot Cognition and Navigation: Experiment with mobile Robot" which has been published in 2007 from Springer-Verlag , German.He has acted as Principal investigator of many projects sponsored by All India Council for Technical Education and University Grants Commission. His name has been placed in the MARQUIS who's who in the World for the year 2004.He has been awarded as the International Educator of the year 2005, by International Biographical Centre, Great Britain.He is the Editor-in -Chief of the International Journal of Information and Communication Technology and International Journal of Computational Vision and Robotics, published by Inderscience Publishing House,England. 


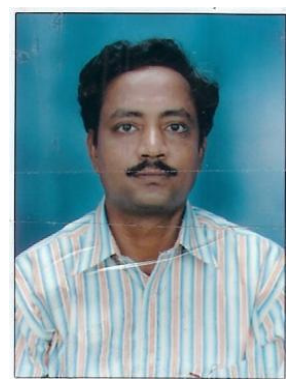

Srikanta Pal was educated at NIT Warangal, where he graduated with a degree in Electronics and Communication Engineering, in 1990, he then post-graduated in Microwave Engineering from Jadavpur University, in 1992. In $2001 \mathrm{He}$ advanced his career in research and academic line by joining The Oxford University in 2001 as a research assistant where he worked in the projects on High temperature superconductors for digital terrestrial television and active and passive retro-reflectors. Simultaneously he continued for his doctoral research. He was awarded DPhil from the Department of Engineering Science of University of Oxford, United Kingdom in 2003 for research into High Temperature Superconducting microwave filters. During 1992 to 2000, he worked in Bharat Electronics Limited (BEL) in the departments of R \&D antenna, Testing Antenna and Microwave Laboratory as Dy Engineer and then Senior Engineer. After leaving Oxford University he joined Centre for Applied Research in Electronics (C.A.R.E.) at the Indian institute of Technology as a Visiting Faculty in 2003. The job was in UG and PG teaching and his research was on RF metamaterials. In 2005, he joined in the department of Electronics and Computer Eng. of Indian institute of Technology, Roorkee as an Assistant Professor. His work in IIT Roorkee was UG and PG teaching and research. In 2006 he joined emerging devices technology (EDT) research center in department of EECE in University of Birmingham under Prof. Mihael J Lancaster as a post doctoral research fellow. His research work at Birmingham was Superconducting filters for radio astronomy and RF MEMS. Since April 2008, he is working as an Associate Professor in Birla Institute of technology, Mesra in the Department of Electronics and Communication Engineering. His present personal research interests include microwave millimeter wave circuits and components and RF MEMS, as well as the high frequency properties and applications of novel and diverse materials. 